\title{
Aneurysmal Neck Clipping as the Primary Treatment Option for Both Ruptured and Unruptured Middle Cerebral Artery Aneurysms
}

\author{
Jai Ho Choi, M.D., Jung Eon Park, M.D., ${ }^{2}$ Myeong Jin Kim, M.D., ${ }^{3}$ Bum Su Kim, M.D., Ph.D., ${ }^{4}$ Yong Sam Shin, M.D., Ph.D. ${ }^{2}$ \\ Department of Neurosurgery, ${ }^{1}$ Chungbuk National University Hospital, Chungbuk National University College of Medicine, Cheongju, Korea \\ Departments of Neurosurgery, ${ }^{2}$ Radiology, ${ }^{4}$ Seoul St. Mary's Hospital, The Catholic University of Korea College of Medicine, Seoul, Korea \\ Department of Neurosurgery, ${ }^{3}$ Gachon University Gil Medical Center, Incheon, Korea
}

\begin{abstract}
Objective : Although middle cerebral artery (MCA) aneurysms are less amenable to coil embolization, an increasing number of studies support favorable endovascular treatment for them. The purpose of this study is to compare the outcomes of two different treatments (surgery versus coiling) and evaluate the benefits of surgical clipping for MCA aneurysms.

Methods : Here we retrospectively analyzed the outcomes of 178 ruptured and unruptured MCA aneurysms treated in patients between September 2008 and April 2012. Parameters assessing treatment outcomes include degree of aneurysm occlusion, presence of regrowth, clinical status, and complications.

Results : Among 178 MCA aneurysms, 153 were treated surgically. After a mean follow-up of 12 months, the surgery group showed a clinically significant complete occlusion rate (98\%) compared with the coiling group (56\%) $(p<0.001)$. Follow-up radiologic evaluation showed a higher regrowth rate (four of 16 cases) in the coiling group than in the surgery group (one of 49 cases) $(p=0.003)$. There was no statistically significant difference in favorable clinical outcome rate between the two groups. The procedure-related permanent morbidity and mortality rates were $2 \%$ (three of 153 cases) in the surgery group and $0 \%$ ( 0 of 25 cases) in the coiling group.

Conclusion : Compared to endovascular treatment, surgical neck clipping for both ruptured and unruptured MCA aneurysms results in a significantly higher complete obliteration rate and less regrowth. Therefore, even in this endovascular era, we still recommend surgical clipping as the primary treatment option for MCA aneurysms rather than coil embolization.
\end{abstract}

Key Words : Intracranial aneurysm · Middle cerebral artery · Surgical clip · Coil embolization.

\section{INTRODUCTION}

In 2002, the International Subarachnoid Aneurysm Trial (ISAT) results showed that the outcomes (absolute risk reduction in dependency or death) of endovascular coiling were significantly better than those of microsurgical treatment after 1 year of follow-up in cases of ruptured aneurysm ${ }^{13)}$. Thereafter, the preferred treatment for almost all aneurysms changed from microsurgical clipping to endovascular coiling. Although the ISAT results were restricted to ruptured intracranial aneurysms and middle cerebral artery (MCA) aneurysms were underrepresented, some institutions currently use coil embolization as the primary treatment option regardless of aneurysm location and the presence or absence of intracranial hemorrhage. Nussbaum et al. ${ }^{15)}$ expressed this trend as the "endovascular era" in his report. However, in some cases, microsurgical clipping is more beneficial than endovascular techniques. MCA aneurysms are traditionally considered more feasible for microsurgical access because of their anatomical location and are less treatable by endovascular techniques because of their specific geometrical characteristics such as a wide neck and branches that are incorporated into the aneurysm neck portion ${ }^{18)}$. But with recent improvements in endovascular instrumentations and techniques such as balloon or stent-assisted coiling, even MCA aneurysms are treated with endovascular techniques as the primary treatment option in several institutes ${ }^{7,11,16,20)}$.

The purpose of this study was to compare our treatment results of MCA aneurysms by surgery or coiling and evaluate the bene-

- Received : June 13, 2015 • Revised : February 12, 2016 • Accepted : February 13, 2016

- Address for reprints : Yong Sam Shin, M.D., Ph.D.

Department of Neurosurgery, Seoul St. Mary's Hospital, The Catholic University of Korea College of Medicine, 222 Banpo-daero, Seocho-gu, Seoul 06591, Korea

Tel : +82-2-2258-6125, Fax : +82-2-594-4248, E-mail : nsshin@catholic.ac.kr

- This is an Open Access article distributed under the terms of the Creative Commons Attribution Non-Commercial License (http://creativecommons.org/licenses/by-nc/3.0) which permits unrestricted non-commercial use, distribution, and reproduction in any medium, provided the original work is properly cited. 
fits of surgical treatment as the primary treatment option for MCA aneurysms.

\section{MATERIALS AND METHODS}

Between September 2008 and April 2012, we treated 178 MCA aneurysms in 170 patients by surgical clipping and endovascular coiling. We reviewed patient information and imaging findings from our prospectively collected aneurysm database that includes demographic, anatomical, outcome, and clinical data. Every surgery was performed by a single neurosurgeon, while all endovascular treatments (EVT) were performed by one neurosurgeon or one interventional neuroradiologist.

\section{Decision of treatment strategy}

The treatment strategy (observation, clip, or coil) was decided by a multidisciplinary neurovascular team composed of expert neurovascular neurosurgeons and a neuroradiologist after discussion. If we expected there to be no definite benefits between the two treatment options (clip or coil) in terms of patient outcome and perioperative complications, we primarily chose microsurgical clipping in cases of MCA aneurysms. EVT were considered in some selected cases that lacked complexity such as a relatively small neck ( $\leq 4 \mathrm{~mm}$ ), large dome-to-neck ratio ( $>1.5)$, no incorporated branches in angiographic findings ${ }^{18,22}$, and/or clinically ruptured aneurysms with a high Hunt-Hess grade and/or use of medications such as warfarin.

All unruptured aneurysms preoperatively underwent cerebral digital subtracted angiography (DSA) including 3-dimensional reconstruction. After analyzing the results of cerebral angiography including aneurysm location, shape, size, presence of vessel incorporation, and geometric configuration, we chose the treatment strategies. In principle, smooth aneurysms (no tubular shape, bleb, or daughter sac) $<5 \mathrm{~mm}$ were treated by observation and follow-up. However, if there was any change in aneurysm size and morphology on follow-up computed tomography angiography (CTA) or magnetic resonance angiography (MRA), we recommended that patients undergo treatment. We treated even small aneurysms when there was a family history, high aspect ratio, and previous aneurysm rupture.

\section{Treatment procedures and postoperative management}

The surgical treatments of all MCA aneurysms were performed by a standard pterional approach under general endotracheal anesthesia. Surgical neck clipping was done in routine microsurgical procedures. We have intraoperatively used a standard somatosensory and motor evoked potential monitoring system since 2010. After aneurysm neck clipping, intraoperative Doppler sonography was used routinely to confirm the parent and branching vessel patency and rule out blood filling of the aneurysmal sac; if needed, we also used indocyanine videoangiography. In EVT cases, we used a single or multiple microcatheter technique without adjunctive techniques such as stent or bal- loon-assisted coil embolization to all MCA aneurysms. We confirmed aneurysmal sac obliteration on immediate postprocedural cerebral angiography.

After the surgical clipping, all patients were routinely cared for in the intensive care unit (ICU) and checked postoperatively with non-enhanced computed tomography within 24 hours to determine the presence of procedure-related complications. The patients treated by coil embolization were also transferred to the ICU postoperatively and checked for complications such as embolic infarction by magnetic resonance diffusion within 24 hours. If there was no complication in unruptured aneurysm cases, the patients were transferred to general ward on postoperative day 1 and discharged within 5-14 hospital days. A follow-up imaging study was performed in an outpatient clinic 4-12 months later. We identified residual sac or aneurysm regrowth using CTA in cases of clipping and MRA in cases of coiling. Follow-up cerebral angiography was only performed with the evidence of aneurysm regrowth or any change in the size or morphology on CTA or MRA.

Clinical outcome was assessed based on Glasgow Outcome Scale (GOS) at discharge and 6 months later in an outpatient clinic. We divided the outcome into favorable outcome (GOS 4-5) and unfavorable outcome (GOS $1-3)^{9)}$. We registered all the procedure-related and perioperative events and compared several parameters such as patient demographics and aneurysm geometry between cases of clipping and coiling.

\section{Statistical analysis}

SPSS version 18 was used for the statistical analysis (SPSS, Inc., an IBM Company, Chicago, IL, USA). We used Student's t-test or Mann-Whitney U test for continuous variables and $\chi^{2}$ or Fisher's exact test for categorical variables for univariate analysis. Multivariate logistic regression analysis was performed to predict the potential risk factors. Null hypotheses of no difference were rejected if $p$ values were $<0.05$.

\section{RESULTS}

\section{Baseline patient and aneurysm characteristics}

Of the total 178 MCA aneurysms, 140 were unruptured and 38 were ruptured. We treated 123 unruptured aneurysms with surgical clipping and 17 cases with endovascular coil embolization. Of the ruptured MCA aneurysms, 30 were treated surgically and eight were treated endovascularly. Baseline patient and aneurysm characteristics are summarized in Table 1. The mean ages of the surgery and EVT group were 54.96 \pm 9.82 and $61.56 \pm 9.32$, respectively, showing that the latter was statistically higher. The most common location of MCA aneurysm was the MCA bifurcation in both groups. Three (2\%) aneurysms in the surgery group and one (4\%) aneurysm in the EVT group were located distal to the MCA bifurcation (M2-3). The mean size was larger and the mean neck size was smaller in the EVT group, but the differences were not significant. However, the dome-to-neck 
Table 1. Comparison of patient and aneurysm characteristics between the surgery and EVT groups

\begin{tabular}{|c|c|c|c|c|c|c|c|c|c|}
\hline \multirow[b]{2}{*}{ Variable } & \multicolumn{3}{|c|}{ Surgery } & \multicolumn{3}{|c|}{ EVT } & \multicolumn{3}{|c|}{$p$ value } \\
\hline & $\begin{array}{l}\text { Unruptured } \\
(\mathrm{n}=123)\end{array}$ & $\begin{array}{l}\text { Ruptured } \\
(\mathrm{n}=30)\end{array}$ & $\begin{array}{c}\text { Total } \\
(\mathrm{n}=153)\end{array}$ & $\begin{array}{l}\text { Unruptured } \\
\quad(\mathrm{n}=17)\end{array}$ & $\begin{array}{c}\text { Ruptured } \\
(\mathrm{n}=8)\end{array}$ & $\begin{array}{l}\text { Total } \\
(\mathrm{n}=25)\end{array}$ & Unruptured & Ruptured & Total \\
\hline Mean age & $55.40 \pm 9.23$ & $53.17 \pm 11.96$ & $54.96 \pm 9.82$ & $60.06 \pm 8.07$ & $64.75 \pm 11.47$ & $61.56 \pm 9.32$ & 0.050 & 0.038 & 0.002 \\
\hline Female & $79(64.2 \%)$ & $18(60 \%)$ & $97(63.4 \%)$ & $13(76.5 \%)$ & $5(62.5 \%)$ & $18(72 \%)$ & 0.419 & 1.000 & 0.404 \\
\hline Hypertension & $62(51.2 \%)$ & $11(36.7 \%)$ & $73(48.3 \%)$ & $9(52.9 \%)$ & $6(75 \%)$ & $15(60 \%)$ & 0.895 & 0.107 & 0.280 \\
\hline Diabetes mellitus & $19(15.7 \%)$ & $1(3.3 \%)$ & $20(13.2 \%)$ & $3(17.6 \%)$ & $2(25 \%)$ & $5(20 \%)$ & 0.735 & 0.106 & 0.370 \\
\hline Smoking & $16(13.2 \%)$ & $2(6.7 \%)$ & $18(11.9 \%)$ & $3(17.6 \%)$ & $2(25 \%)$ & $5(20 \%)$ & 0.705 & 0.189 & 0.267 \\
\hline Mean f/u period, months & $10.38 \pm 10.47$ & $17.17 \pm 11.81$ & $11.73 \pm 11.05$ & $11.71 \pm 12.80$ & $14.20 \pm 13.66$ & $12.27 \pm 11.71$ & 0.635 & 0.598 & 0.833 \\
\hline Mean hospital days & $9.39 \pm 4.63$ & $18.87 \pm 13.62$ & $11.25 \pm 8.18$ & $7.59 \pm 9.91$ & $18.00 \pm 7.34$ & $10.92 \pm 10.28$ & 0.210 & 0.538 & 0.858 \\
\hline Mean size & $5.11 \pm 2.34$ & $6.61 \pm 3.91$ & $5.39 \pm 2.75$ & $5.23 \pm 1.60$ & $8.24 \pm 2.77$ & $6.19 \pm 2.45$ & 0.829 & 0.070 & 0.174 \\
\hline Location & & & & & & & 0.010 & 0.833 & 0.179 \\
\hline M1 & $11(8.9 \%)$ & $1(3.3 \%)$ & $12(7.8 \%)$ & $5(29.4 \%)$ & $0(0 \%)$ & $5(20 \%)$ & & & \\
\hline MCA bifurcation & $111(90.2 \%)$ & $27(90 \%)$ & $138(90.2 \%)$ & $11(64.7 \%)$ & $8(100 \%)$ & $19(76 \%)$ & & & \\
\hline M2-3 & $1(0.8 \%)$ & $2(6.6 \%)$ & $3(2 \%)$ & $1(5.9 \%)$ & $0(0 \%)$ & $1(4 \%)$ & & & \\
\hline Neck size & $3.97 \pm 1.66$ & $4.28 \pm 2.91$ & $4.03 \pm 1.95$ & $3.22 \pm 0.73$ & $4.79 \pm 1.93$ & $3.72 \pm 1.42$ & 0.069 & 0.168 & 0.450 \\
\hline Dome-to-neck ratio & $1.23 \pm 0.29$ & $1.45 \pm 0.63$ & $1.27 \pm 0.39$ & $1.50 \pm 0.25$ & $1.63 \pm 0.37$ & $1.54 \pm 0.29$ & $<0.001$ & 0.125 & 0.001 \\
\hline Aspect ratio & $0.96 \pm 0.37$ & $1.35 \pm 0.57$ & $1.04 \pm 0.44$ & $1.52 \pm 0.28$ & $1.69 \pm 0.54$ & $1.57 \pm 0.38$ & $<0.001$ & 0.070 & $<0.001$ \\
\hline Broad neck ( $\geq 4 \mathrm{~mm}$ ) & $47(38.2 \%)$ & $11(36.7 \%)$ & $58(37.9 \%)$ & $3(17.6 \%)$ & $5(62.5 \%)$ & $8(32 \%)$ & 0.113 & 0.243 & 0.571 \\
\hline \multicolumn{10}{|l|}{ Vessel incorporation } \\
\hline No incorporation & $13(11.7 \%)$ & $5(17.2 \%)$ & $18(12.9 \%)$ & $6(35.3 \%)$ & $2(25 \%)$ & $8(32 \%)$ & 0.011 & 0.631 & 0.016 \\
\hline Early branch & $13(11.7 \%)$ & $1(3.4 \%)$ & $14(10 \%)$ & $5(29.4 \%)$ & $0(0 \%)$ & $5(20 \%)$ & & & \\
\hline Both divisions & $20(18 \%)$ & $7(24.1 \%)$ & $27(19.3 \%)$ & $0(0 \%)$ & $3(37.5 \%)$ & $3(12 \%)$ & & & \\
\hline Superior division & $32(28.8 \%)$ & $12(41.4 \%)$ & $44(31.4 \%)$ & $2(11.8 \%)$ & $2(25 \%)$ & $4(16 \%)$ & & & \\
\hline Inferior division & $33(29.7 \%)$ & $4(13.8 \%)$ & $37(26.4 \%)$ & $4(23.5 \%)$ & $1(12.5 \%)$ & $5(20 \%)$ & & & \\
\hline
\end{tabular}

EVT : endovascular treatment, f/u : follow-up, MCA : middle cerebral artery

ratio, aspect ratio, and presence of vessel incorporation differed significantly between the surgery and EVT groups.

\section{Aneurysm neck remnants and radiological outcome}

The univariate and multivariate logistic regression analysis results of the association with aneurysm neck remnants are shown in Table 2. Treatment modality (surgery or EVT), rupture status, age, aneurysm size, aneurysm location, dome-to-neck ratio, and aspect ratio were significantly different between the complete obliteration group and the neck remnant group on univariate analysis. Multivariate logistic regression analysis was performed for variables that were significantly associated with neck remnants $(p<0.05)$ and had marginal $p$ values $(p<0.01)$ on univariate analysis. The multivariate analysis results showed that the following factors were significantly associated with aneurysm neck remnants $(p<0.05)$ : treatment modality [odds ratio (OR), 92.699; 95\% confidence interval (CI), 5.805-1480.177], age (OR, 1.171 ; 95\% CI, 1.008-1.360), and mean size (OR, 1.753; 95\% CI, 1.219-2.521).

The comparisons of radiological outcomes between the surgery and EVT groups are summarized in Table 3. Of the total 153 aneurysms in the surgery group, three had neck remnants. Of the three neck remnant cases, two developed in the unruptured aneurysm group. The causes of neck remnants were fusi- form aneurysm shape in one case and compromise of inferior division arising from the aneurysm neck portion in the other cases. After more than 12 months of follow-up, neither was seen as growing on CTA or developed other complications including re-bleeding. One remnant neck case of ruptured aneurysms was a large aneurysm with a 22-mm maximal diameter. The initial neurological status of this patient was coma, and she died of severe brain swelling during the postoperative course. Consequently, the complete aneurysm sac obliteration rate in the surgery group was $98 \%$ (150 of 153 aneurysms), whereas the EVT group showed a $56 \%$ (14 of 25 aneurysms) complete aneurysm sac obliteration rate, a statistically significant difference between groups $(p<0.001)$ (Table 3$)$. There were six neck remnants in the unruptured aneurysm group and five in the ruptured group. We analyzed the potential risk factors including rupture status, age, aneurysm location, aneurysm size, neck diameter, aspect ratio, dome-to-neck ratio, presence of vessel incorporation, and packing density for incomplete obliteration in EVT group. Univariate analysis showed that age $(p=0.018)$, aspect ratio $(p=0.009)$, and presence of vessel incorporation ( $p=0.042)$ differed significantly between the complete obliteration group and neck remnant group. However, multivariate logistic regression analysis revealed no statistically significant factors related to incomplete obliteration.

We obtained follow-up CTA and/or DSA in 49 of 153 aneu- 
Table 2. Uni- and multivariate analysis of association between MCA aneurysm and neck remnants

\begin{tabular}{|c|c|c|c|c|c|c|}
\hline Variables & $\begin{array}{l}\text { Complete obliteration } \\
\qquad(\mathrm{n}=164)\end{array}$ & $\begin{array}{l}\text { Neck remnants } \\
\quad(\mathrm{n}=14)\end{array}$ & Univariate & Multivariate & Odds ratio & $95 \% \mathrm{CI}$ \\
\hline Treatment modality & & & $<0.001$ & 0.001 & 92.699 & $5.805-1480.177$ \\
\hline Surgery & $150(91.5 \%)$ & $3(21.4 \%)$ & & & & \\
\hline EVT & $14(8.5 \%)$ & $11(78.6 \%)$ & & & & \\
\hline Rupture status & $131(79.8 \%)$ & $8(57.1 \%)$ & 0.048 & 0.894 & & \\
\hline Age & $55.20 \pm 9.79$ & $64.00 \pm 8.99$ & 0.003 & 0.038 & 1.171 & $1.008-1.360$ \\
\hline Female & $103(62.8 \%)$ & $12(85.7 \%)$ & 0.143 & & & \\
\hline Hypertension & $79(48.8 \%)$ & $9(64.3 \%)$ & 0.404 & & & \\
\hline Diabetes mellitus & $21(13 \%)$ & $4(28.6 \%)$ & 0.177 & & & \\
\hline Smoking & $21(13 \%)$ & $2(14.3 \%)$ & 1.000 & & & \\
\hline Mean size & $5.29 \pm 2.37$ & $8.10 \pm 4.86$ & 0.005 & 0.002 & 1.753 & $1.219-2.521$ \\
\hline Neck size & $3.92 \pm 1.62$ & $4.87 \pm 3.91$ & 0.861 & & & \\
\hline Location & & & 0.086 & 0.236 & & \\
\hline M1 & $13(7.9 \%)$ & $4(28.6 \%)$ & & & & \\
\hline MCA bifurcation & $147(89.6 \%)$ & $10(71.4 \%)$ & & & & \\
\hline $\mathrm{M} 2-3$ & $4(2.4 \%)$ & $0(0 \%)$ & & & & \\
\hline Dome-to-neck ratio & $1.29 \pm 0.38$ & $1.53 \pm 0.39$ & 0.023 & 0.174 & & \\
\hline Aspect ratio & $1.07 \pm 0.44$ & $1.71 \pm 0.46$ & $<0.001$ & 0.052 & & \\
\hline Broad neck & $61(37.2 \%)$ & $6(42.9 \%)$ & 0.675 & & & \\
\hline Vessel incorporation & $126(83.4 \%)$ & $13(92.9 \%)$ & 0.700 & & & \\
\hline
\end{tabular}

MCA : middle cerebral artery, $\mathrm{Cl}$ : confidence interval, EVT : endovascular treatment

Table 3. Comparison of radiological outcomes between surgery and EVT groups

\begin{tabular}{|c|c|c|c|c|c|}
\hline & & Initial & $<12$ months & $\geq 12$ months & $p$ value \\
\hline \multirow[t]{4}{*}{ Surgery $(n=153)$} & Complete obliteration & $150(98 \%)^{*}$ & & & $<0.001^{\star}$ \\
\hline & Neck remnant & 3 & & & \\
\hline & Regrowth & & $\begin{array}{l}1(2 \% \text {; one of } 49 \text { aneurysms } \\
\text { on f/u imaging })^{\dagger}\end{array}$ & $\begin{array}{l}0(0 \% ; 0 \text { of } 23 \text { aneurysms } \\
\text { on } \mathrm{f} / \mathrm{u} \text { imaging })\end{array}$ & $0.003^{\dagger}$ \\
\hline & Retreatment & & 1 & 0 & \\
\hline \multirow[t]{4}{*}{$\mathrm{EVT}(\mathrm{n}=25)$} & Complete obliteration & $14(56 \%)^{*}$ & & & \\
\hline & Neck remnant & 11 & & & \\
\hline & Regrowth & & $\begin{array}{l}4(25 \% \text {; four of } 16 \text { aneurysms } \\
\text { on } \mathrm{f} / \mathrm{u} \text { imaging })^{\dagger}\end{array}$ & $\begin{array}{l}0 \text { ( } 0 \% ; 0 \text { of eight aneurysms } \\
\text { on } \mathrm{f} / \mathrm{u} \text { imaging) }\end{array}$ & \\
\hline & Retreatment & & 0 & 0 & \\
\hline
\end{tabular}

Comparison between surgery and EVT for *initial degree of aneurysm obliteration and ${ }^{\dagger}$ aneurysm regrowth within 12 months after treatment. f/u : follow-up, EVT : endovascular treatment

rysms treated with surgery and MRA and/or DSA in 16 of 25 aneurysms treated with EVT within 12 months after treatment. Of the 49 aneurysms treated with surgery, one (2\%) aneurysm located in the distal MCA (M3-4) showed regrowth and was retreated by surgical resection and superficial temporal arteryMCA bypass surgery. We obtained 23 additional follow-up images more than 12 months later and noted no aneurysm regrowth. In the EVT group, the aneurysm regrowth rate was 25\% (four of 16 aneurysms), showing a significant difference between the surgery and EVT groups ( $p=0.003)$. Two cases occurred in the unruptured EVT group, while the others occurred in the ruptured group. There were two cases of aneurysm regrowth with incomplete obliteration and two cases of aneurysm regrowth with complete obliteration. Regarding size and shape, no addi- tional treatment was performed in any case and no complications including aneurysm rupture developed. We obtained eight additional follow-up images $>12$ months later and detected no aneurysm regrowth.

\section{Procedure-related and perioperative complications}

Perioperative and periprocedural complications are described in Table 4. In the surgery group, 17 (11.1\%) complications were recorded. There were $10(8.1 \%)$ cases in the unruptured group and seven $(23.3 \%)$ in the ruptured group. Two cases in the unruptured surgery group required additional surgery for symptomatic hemorrhage. There was one case of postoperative epidural hematoma that presented as hemiparesis; after a second operation, the patient fully recovered without sequelae. Another 
Table 4. Perioperative and periprocedural complications

\begin{tabular}{|c|c|c|c|c|c|c|c|c|c|}
\hline & \multicolumn{3}{|c|}{ Surgery $(n=153)$} & \multicolumn{3}{|c|}{$\operatorname{EVT}(n=25)$} & \multicolumn{3}{|c|}{$p$ value } \\
\hline & $\begin{array}{l}\text { Unruptured } \\
(\mathrm{n}=123)\end{array}$ & $\begin{array}{c}\text { Ruptured } \\
(\mathrm{n}=30)\end{array}$ & Total & $\begin{array}{l}\text { Unruptured } \\
(\mathrm{n}=17)\end{array}$ & $\underset{(\mathrm{n}=8)}{\text { Ruptured }}$ & Total & Unruptured & Ruptured & Total \\
\hline Asymptomatic hemorrhage on CT scan & 8 & 1 & 9 & - & - & & & & \\
\hline Symptomatic postoperative bleeding & 2 & 2 & 4 & - & - & & & & \\
\hline Clinical vasospasm & - & 2 & 2 & - & 2 & 2 & & & \\
\hline Hydrocephalus & - & 2 & 2 & - & - & & & & \\
\hline $\begin{array}{l}\text { Asymptomatic embolic infarction } \\
\text { on MR diffusion }\end{array}$ & - & - & & 5 & - & 5 & & & \\
\hline $\begin{array}{l}\text { Asymptomatic intraprocedural } \\
\text { rupture }\end{array}$ & - & - & & 1 & - & 1 & & & \\
\hline Total complications & $10(8.1 \%)$ & $7(23.3 \%)$ & $17(11.1 \%)$ & $6(35 \%)$ & $2(25 \%)$ & $8(32 \%)$ & $<0.001$ & 1.000 & 0.005 \\
\hline $\begin{array}{l}\text { Procedure-related morbidity and } \\
\text { mortality }\end{array}$ & $1(0.08 \%)$ & $2(6.7 \%)$ & $3(2 \%)$ & 0 & 0 & 0 & 1.000 & 1.000 & 1.000 \\
\hline
\end{tabular}

EVT : endovascular treatment, CT : computed tomography, MR : magnetic resonance

Table 5. Clinical outcome

\begin{tabular}{|c|c|c|c|c|c|c|}
\hline \multirow[b]{2}{*}{ Variables } & \multicolumn{2}{|c|}{ Surgery $(\mathrm{n}=153)$} & \multicolumn{2}{|c|}{$\operatorname{EVT}(n=25)$} & \multicolumn{2}{|c|}{$p$ value } \\
\hline & $\begin{array}{l}\text { Unruptured } \\
(\mathrm{n}=123)\end{array}$ & $\begin{array}{c}\text { Ruptured } \\
(\mathrm{n}=30)\end{array}$ & $\begin{array}{l}\text { Unruptured } \\
(\mathrm{n}=17)\end{array}$ & $\begin{array}{c}\text { Ruptured } \\
(\mathrm{n}=8)\end{array}$ & Unruptured & Ruptured \\
\hline Hunt-Hess grade $($ mean $\pm \mathrm{SD})$ & & $2.53 \pm 1.13$ & & $2.88 \pm 1.12$ & & 0.454 \\
\hline Hunt-Hess 1-3 (\%) & & $23(77 \%)$ & & $6(75 \%)$ & & 1.000 \\
\hline GOS (mean \pm SD) & $4.97 \pm 0.36$ & $4.67 \pm 0.87$ & 5 & $4.17 \pm 0.75$ & 0.711 & 0.206 \\
\hline GOS 4-5 (\%) & $104 / 105(99 \%)$ & $25 / 29(86 \%)$ & $15 / 15(100 \%)$ & $5 / 6(83 \%)$ & 1.000 & 1.000 \\
\hline
\end{tabular}

EVT : endovascular treatment, GOS : Glasgow Outcome Scale, SD : standard deviation

patient died of postoperative intracranial hemorrhage and progressive brain swelling, representing the only procedure-related mortality case in the surgery group. Other complications in the unruptured surgery group consisted of asymptomatic brain contusions and/or remote hemorrhages. In the ruptured surgery group, two patients underwent additional surgery for postoperative hemorrhage and suffered permanent morbidity as a result. There was an overall 2\% (three patients) permanent morbidity and mortality rate related to surgical treatment.

In the EVT group, eight (32\%) complications developed (25\% in the ruptured group and 35\% in the unruptured group), including one asymptomatic intraprocedural aneurysm rupture and five asymptomatic embolic infarction, as observed on magnetic resonance diffusion imaging. There were no cases of procedurerelated morbidity and mortality in the EVT group. Symptomatic vasospasm was observed in four of 38 patients who presented with subarachnoid hemorrhage regardless of treatment method.

\section{Clinical outcome}

Clinical outcomes are shown in Table 5. At the last follow-up, a favorable outcome after treatment for ruptured aneurysms was achieved in 25 of 29 patients treated surgically (86\%) and in five of six patients treated endovascularly (83\%). In the unruptured group, all patients except one in the surgery group had favorable outcomes regardless of treatment modality. There was no statistically significant difference between the two groups.

\section{DISCUSSION}

Johnston et al. ${ }^{10)}$ analyzed the association between incomplete aneurysm occlusion and aneurysm re-rupture after $\mathrm{SAH}$ and found that cumulative re-rupture risk is $1.1 \%$ for complete occlusion, $2.9 \%$ for $91-99 \%$ occlusion, $5.9 \%$ for $70-90 \%$ occlusion, and $17.6 \%$ for $<70 \%$ occlusion. They noted that the overall re-rupture risk tended to be greater after coil embolization than after surgical clipping ( $3.4 \%$ vs. $1.3 \%, p=0.092)$. Consequently, the final goal of rupture and unruptured aneurysm treatment should be complete aneurysm sac obliteration. We treated 178 MCA aneurysms and achieved a 98\% complete aneurysm obliteration rate in the surgery group. On the other hand, the complete aneurysm obliteration rate was $56 \%$ in the EVT group. Similar to our results, Güresir et al. ${ }^{8)}$ reported complete obliteration rates of $97.4 \%$ for surgery and $52.5 \%$ for EVT after analyzing 330 aneurysms. In addition, van Dijk et al. ${ }^{21)}$ reported a complete occlusion rate of $89 \%$ in 107 surgically treated aneurysms. The complete obliteration rate of MCA aneurysms treated endovascularly reportedly varied from $26.3 \%$ to $67 \%$ and outcomes were not better than surgical outcomes ${ }^{2,7,11,16,20)}$. EVT has a higher rate of remnant necks than surgery due to the specific configurations of MCA aneurysms, which are characterized by a small dome-to-neck ratio, a relatively wide neck, and the possibility that one of the branches might be incorporated in the aneurysm's neck. Advanced techniques such as stent- and balloon-assisted coil 
embolization are commonly used to compensate for the disadvantages of general coil embolization. Some authors reported efficacy and good outcomes for wide-neck MCA aneurysms subjected to stent-assisted coil embolization ${ }^{1,5,25)}$. However, this technique has several limitations and procedure-related complications. In MCA aneurysms, there are many small perforators that sometimes preclude stent application. The main drawback of this technique is an increased possibility of thromboembolic events during the periprocedural period ${ }^{18,23,24)}$. In addition, because delayed severe in-stent stenosis, a rare but potentially devastating complication, can occur, patients must be closely observed and followed ${ }^{6,24)}$. Consequently, if stent-assisted coil embolization is performed, antiplatelet agents should be taken for several months to prevent thromboembolic events.

Aneurysm recanalization develops more frequently with endovascular coil embolization than with microsurgical treatment because of the high frequency of remnant neck and coil compaction and/or loosening ${ }^{3,13)}$. After complete aneurysm coiling, the recanalization rate was reportedly between $8 \%$ and $27.2 \%$,7,16,20,22). Choi et al. ${ }^{4)}$ announced that the overall recanalization rate of aneurysms regardless of location was $26.4 \%$ (24 of 91 aneurysms), whereas that of the MCA bifurcation, the most common site, was $75 \%$ (three of four aneurysms). The reported retreatment rates after coil embolization range from $4 \%$ to $10.5 \%{ }^{4,7,16,20,22}$. The Cerebral Aneurysm Rerupture After Treatment study noted that the annual retreatment rate was $13.3 \%$ for coiling and $2.6 \%$ for clipping in the first year $(p<0.0001)$ and that no surgically treated aneurysm required retreatment after the first year, while the retreatment rate for coil embolization was $4.5 \%$ in the second year and $1.1 \%$ annually after the third year $(p<0.0001)^{3)}$. In addition, recent reports of long-term ISAT results showed that the coil embolization outcomes are not superior to surgical treatment after 5-year follow-up because of higher re-bleeding and retreatment rates after coil embolization ${ }^{10,12,19)}$. Procedure-related morbidity and mortality rates of surgical neck clipping for unruptured MCA aneurysms in our series were low as already reported elsewhere $(0.6-5 \%)^{14,17)}$.

The limitations of this study include that it was performed retrospectively at a single institution and that the number of patients in the EVT group may not be large enough to draw definite conclusions about the comparison of radiological and clinical outcomes between the surgery and EVT groups. Additionally, selection bias and a wide CI could exist because we decided treatment modalities based on our treatment strategy without randomization. Further prospective large-volume randomized data should be investigated to exclude any limitations.

\section{CONCLUSION}

Decisions of treatment strategies for intracranial aneurysms remain controversial but recent trends favor EVT over microsurgical clipping. However, in cases of MCA aneurysms, we can easily access the aneurysm surgically and obtain high complete obliteration rates and low recurrence and retreatment rates with reasonable morbidity and mortality rates. Although further investigations are needed, it is worth considering surgical neck clipping as the primary treatment option for MCA aneurysms.

\section{References}

1. Biondi A, Janardhan V, Katz JM, Salvaggio K, Riina HA, Gobin YP : Neuroform stent-assisted coil embolization of wide-neck intracranial aneurysms : strategies in stent deployment and midterm follow-up. Neurosurgery 61 : 460-468; discussion 468-469, 2007

2. Brinjikji W, Lanzino G, Cloft HJ, Rabinstein A, Kallmes DF : Endovascular treatment of middle cerebral artery aneurysms : a systematic review and single-center series. Neurosurgery 68 : 397-402; discussion 402, 2011

3. CARAT Investigators : Rates of delayed rebleeding from intracranial aneurysms are low after surgical and endovascular treatment. Stroke 37 : 1437-1442, 2006

4. Choi DS, Kim MC, Lee SK, Willinsky RA, Terbrugge KG : Clinical and angiographic long-term follow-up of completely coiled intracranial aneurysms using endovascular technique. J Neurosurg 112 : 575-581, 2010

5. Fields JD, Brambrink L, Dogan A, Helseth EK, Liu KC, Lee DS, et al. : Stent assisted coil embolization of unruptured middle cerebral artery aneurysms. J Neurointerv Surg 5 : 15-19, 2013

6. Fiorella D, Albuquerque FC, Deshmukh VR, McDougall CG : In-stent stenosis as a delayed complication of neuroform stent-supported coil embolization of an incidental carotid terminus aneurysm. AJNR Am J Neuroradiol 25 : 1764-1767, 2004

7. Guglielmi G, Viñuela F, Duckwiler G, Jahan R, Cotroneo E, Gigli R : Endovascular treatment of middle cerebral artery aneurysms. Overall perioperative results. Apropos of 113 cases. Interv Neuroradiol 14 : 241-245, 2008

8. Güresir E, Schuss P, Berkefeld J, Vatter H, Seifert V : Treatment results for complex middle cerebral artery aneurysms. A prospective single-center series. Acta Neurochir (Wien) 153 : 1247-1252, 2011

9. Jennett B, Bond $\mathrm{M}$ : Assessment of outcome after severe brain damage. Lancet 1 : 480-484, 1975

10. Johnston SC, Dowd CF, Higashida RT, Lawton MT, Duckwiler GR, Gress DR; CARAT Investigators : Predictors of rehemorrhage after treatment of ruptured intracranial aneurysms : the Cerebral Aneurysm Rerupture After Treatment (CARAT) study. Stroke 39 : 120-125, 2008

11. Kim BM, Kim DI, Park SI, Kim DJ, Suh SH, Won YS : Coil embolization of unruptured middle cerebral artery aneurysms. Neurosurgery 68 : 346353; discussion 353-354, 2011

12. Mitchell P, Kerr R, Mendelow AD, Molyneux A : Could late rebleeding overturn the superiority of cranial aneurysm coil embolization over clip ligation seen in the International Subarachnoid Aneurysm Trial? J Neurosurg 108 : 437-442, 2008

13. Molyneux A, Kerr R, International Subarachnoid Aneurysm Trial (ISAT) Collaborative Group, Stratton I, Sandercock P, Clarke M, et al. : International Subarachnoid Aneurysm Trial (ISAT) of neurosurgical clipping versus endovascular coiling in 2143 patients with ruptured intracranial aneurysms : a randomized trial. J Stroke Cerebrovasc Dis 11 : 304-314, 2002

14. Moroi J, Hadeishi H, Suzuki A, Yasui N : Morbidity and mortality from surgical treatment of unruptured cerebral aneurysms at Research Institute for Brain and Blood Vessels-Akita. Neurosurgery 56 : 224-231; discussion 224-231, 2005

15. Nussbaum ES, Madison MT, Myers ME, Goddard J : Microsurgical treatment of unruptured intracranial aneurysms. A consecutive surgical experience consisting of 450 aneurysms treated in the endovascular era. Surg Neurol 67 : 457-464; discussion 464-466, 2007

16. Quadros RS, Gallas S, Noudel R, Rousseaux P, Pierot L : Endovascular 
treatment of middle cerebral artery aneurysms as first option : a single center experience of 92 aneurysms. AJNR Am J Neuroradiol 28 : 1567 1572,2007

17. Raaymakers TW, Rinkel GJ, Limburg M, Algra A : Mortality and morbidity of surgery for unruptured intracranial aneurysms : a meta-analysis. Stroke 29 : 1531-1538, 1998

18. Regli L, Uske A, de Tribolet N : Endovascular coil placement compared with surgical clipping for the treatment of unruptured middle cerebral artery aneurysms : a consecutive series. J Neurosurg 90 : 1025-1030, 1999

19. Ryttlefors M, Enblad P, Kerr RS, Molyneux AJ : International subarachnoid aneurysm trial of neurosurgical clipping versus endovascular coiling : subgroup analysis of 278 elderly patients. Stroke 39 : 2720-2726, 2008

20. Suzuki S, Tateshima S, Jahan R, Duckwiler GR, Murayama Y, Gonzalez NR, et al. : Endovascular treatment of middle cerebral artery aneurysms with detachable coils : angiographic and clinical outcomes in 115 consecutive patients. Neurosurgery 64 : 876-888; discussion 888-889, 2009

21. van Dijk JM, Groen RJ, Ter Laan M, Jeltema JR, Mooij JJ, Metzemaekers
JD : Surgical clipping as the preferred treatment for aneurysms of the middle cerebral artery. Acta Neurochir (Wien) 153 : 2111-2117, 2011

22. Vendrell JF, Menjot N, Costalat V, Hoa D, Moritz J, Brunel H, et al. : Endovascular treatment of 174 middle cerebral artery aneurysms : clinical outcome and radiologic results at long-term follow-up. Radiology 253 : 191-198, 2009

23. Yahia AM, Gordon V, Whapham J, Malek A, Steel J, Fessler RD : Complications of Neuroform stent in endovascular treatment of intracranial aneurysms. Neurocrit Care $8:$ 19-30, 2008

24. Yahia AM, Latorre J, Gordon V, Whapham J, Malek A, Fessler RD : Thromboembolic events associated with Neuroform stent in endovascular treatment of intracranial aneurysms. J Neuroimaging 20 : 113-117, 2010

25. Yang P, Liu J, Huang Q, Zhao W, Hong B, Xu Y, et al. : Endovascular treatment of wide-neck middle cerebral artery aneurysms with stents : a review of 16 cases. AJNR Am J Neuroradiol 31 : 940-946, 2010 